\title{
The comparative study of fibrin degradation products in normal pregnancy and pregnancy induced hypertension
}

\author{
Rajani Upadhyaya $^{1}$, Anitha Sannaboraiah ${ }^{2 *}$, Kasturi V. Donimath ${ }^{3}$
}

\begin{abstract}
${ }^{1}$ Department of Obstetrics and Gynecology, Sri Satya Sai Hospital, Puttaparthi, Anantapur, Andhra Pradesh, India ${ }^{2}$ Department of Obstetrics and Gynecology, Jindal Sanjeevani Hospital, Toranagallu, Bellary, Karnataka, India ${ }^{3}$ Department of Obstetrics and Gynecology, KIMS, Hubli, Karnataka, India
\end{abstract}

Received: 26 February 2017

Revised: 08 March 2017

Accepted: 11 March 2017

\section{*Correspondence:}

Anitha Sannaboraiah,

E-mail: sanitha96@yahoo.in

Copyright: () the author(s), publisher and licensee Medip Academy. This is an open-access article distributed under the terms of the Creative Commons Attribution Non-Commercial License, which permits unrestricted non-commercial use, distribution, and reproduction in any medium, provided the original work is properly cited.

\begin{abstract}
Background: Pregnancy induced hypertension is a multisystem disorder and is characterized by changes in haemostatic system. The assessment of the coagulation parameters of the patients of pre-eclampsia and eclampsia is important because it helps to diagnose the severity of the disease, and to predict the outcome. There is no universal agreement as to the need for further investigations if the platelet count comes normal. Hence in such cases it is always prudent to get the coagulation profile. D dimer of such patients is done to diagnose the cases of coagulation failure early and to manage it efficiently. The objectives of the study to compare the Fibrin Degradation Products in term normal pregnancy, pre eclamptic and eclamptic patients, to assess the severity of pregnancy induced hypertension and to detect coagulation failure early and manage before it worsens.

Methods: This study was conducted in the Department of Obstetrics and Gynaecology at Karnataka Institute of Medical Sciences, Hubli during the period of March 2014 to February 2015 on 100 patients between 37-42 weeks of gestation. 50 controls were well matched with the study population which included a total of 50 patients with preeclampsia and eclampsia. Pregnant women with known bleeding disorders, on anticoagulant therapy, with abruptio placentae, with IUD, in labour and with established DIC were excluded.

The blood coagulation parameters which were compared between the control and the study population were Bleeding time (BT), Platelet Count, Clotting time (CT), Prothrombin time (PT), Activated partial thromboplastin time (aPTT) and D-dimer.

Results: The BT, CT, PT, aPTT values were nearly identical in all the groups. The platelet count showed a decreasing trend from normal control to eclampsia group. The D dimer showed an increasing trend from the normal control to eclampsia group. D dimer level was raised in all patients who were in sub clinical and clinical coagulation failure.

Conclusions: This study shows that even with the normal routine coagulation parameters, D dimer was significantly elevated in both subclinical and clinical DIC. So, D dimer can be used as a specific tool in early diagnosis and deciding appropriate management of PIH.
\end{abstract}

Keywords: Coagulation profile, D dimer, Eclampsia, Pre-eclampsia

\section{INTRODUCTION}

Normal pregnancy is associated with changes in the haemostatic mechanism with increased levels of the coagulation factors and suppression of fibrinolysis. ${ }^{1}$
Therefore pregnancy is considered to be a state of hypercoagulability. ${ }^{2}$ This modification of the coagulation system is to ensure rapid and effective control of bleeding from the placental site and to prevent fatal hemorrhage during delivery and puerperium. ${ }^{3}$ 
Hypertensive disorders complicate 5\%-10\% of all pregnancies and together they form one member of the deadly triad, along with haemorrhage and infection that contribute greatly to the maternal morbidity and mortality rates. $^{4}$ Out of which pre-eclampsia and eclampsia constitutes $70 \%$ and chronic hypertension $30 \%$. There is a distinct possibility of accentuation of the hypercoagulable state of pregnancy during eclampsia and pre-eclampsia. ${ }^{5}$ There is a physiological balance between the blood coagulation and fibrinolytic mechanisms which maintains an intact patent vascular system. Imbalance in these mechanisms either diminished coagulation or excessive fibrinolysis may lead to failure of hemostasis.

There is considerable evidence to support the fact that intravascular coagulation occurs in severe pre-eclampsia and eclampsia. Post mortem studies in women who died of eclampsia have shown fibrin deposition in the blood vessels of several organs. Renal biopsy specimen by immunofluorescence has demonstrated deposition of fibrinogen related material within renal glomeruli. Further support has come from demonstration of high molecular weight fibrin complexes in the plasma of women with severe pre-eclampsia and eclampsia. There have been many reports of changes in blood coagulation and fibrinolysis compatible with a process of intravascular coagulation in severe pre-eclampsia and eclampsia. In these patients, varying degrees of disseminated intravascular coagulation can contribute significantly to the morbidity and sometimes even to mortality. Early assessment of severity of pre-eclampsia and eclampsia is necessary to prevent complications and increased maternal and fetal morbidity and mortality. Hence this prospective study is undertaken to assess the severity of pre-eclampsia, eclampsia, coagulopathy using fibrin degradation products so that they will guide us for the management and for preventing complications of the pregnancy induced hypertension.

\section{METHODS}

\section{Source of data}

The study includes normotensive pregnant women with signs and symptoms of preeclampsia and eclampsia between 37-42 weeks of gestation attending OPD of our hospital extending from March 2014 to February 2015.

\section{Inclusion criteria}

The study includes normotensive pregnant women between 37-42 weeks of gestation. The study includes pregnant women with signs and symptoms of preeclampsia and eclampsia between 37- 42 weeks of gestation.

\section{Exclusion criteria for pregnant women}

- With known bleeding disorders.

- On anticoagulant therapy.

- With abruption placentae.

- With IUD

- In labour

- With established DIC

\section{Methods of collection of data}

Careful history and detailed clinical examination was done at the time of admission. Following Blood Investigations done

- Routine blood investigations.

- Coagulation profile.

- Fibrin Degradation products.

\section{Statistical methods applied}

- Descriptive analysis

- T-test

- Chi-square test

- Analysis of variance (ANOVA)

\section{RESULTS}

The $\mathrm{p}$ value of chi-square test is less than 0.0001 , indicates there is high association between symptoms and APE (Table 1).

Out of 32 patients in the group SPE, $30(93.75 \%)$ patients had swelling of lower limbs, $12(37.50 \%)$ had generalized edema, $9(28.13 \%)$ had headache and $3(9.38 \%)$ had epigastric pain. Only $1(3.13 \%)$ out of 32 patients had visual disturbances and Vomiting. The $\mathrm{p}$ value of chisquare test is less than 0.0001, indicates there is high association between symptoms and SPE (Table 2).

Table 1: Distribution of patients in group APE according to symptoms.

\begin{tabular}{|c|c|c|c|c|c|c|}
\hline \multirow{2}{*}{ Symptoms } & \multicolumn{4}{|c|}{ Symptoms status among patients } & \multirow{2}{*}{ n } & \multirow{2}{*}{$\begin{array}{l}\text { p- } \\
\text { value }\end{array}$} \\
\hline & Present & $\%$ & Absent & $\%$ & & \\
\hline Headache & 14 & 77.78 & 4 & 22.22 & 18 & \multirow{6}{*}{$<0.000$} \\
\hline Swelling of lower limbs & 17 & 94.44 & 1 & 5.56 & 18 & \\
\hline Visual disturbances & 2 & 11.11 & 16 & 88.89 & 18 & \\
\hline Vomiting & 6 & 33.33 & 12 & 66.67 & 18 & \\
\hline Epigastric pain & 4 & 22.22 & 14 & 77.78 & 18 & \\
\hline Generalised edema & 14 & 77.78 & 4 & 22.22 & 18 & \\
\hline
\end{tabular}


Table 2: Distribution of patients in group SPE according to symptoms.

\begin{tabular}{|lllllll|}
\hline \multirow{2}{*}{ Symptoms } & Symptoms status among patients & & & & p-value \\
\cline { 2 - 7 } & Present & $\mathbf{\%}$ & Absent & \% & n \\
\hline Headache & 9 & 28.13 & 23 & 71.88 & 32 \\
\hline Swelling of lower limbs & 30 & 93.75 & 2 & 6.25 & 32 \\
\hline Visual disturbances & 1 & 3.13 & 31 & 96.88 & 32 \\
\hline Vomiting & 1 & 3.13 & 31 & 96.88 & 32 \\
\hline Epigastric pain & 3 & 9.38 & 29 & 90.63 & 32 \\
\hline Generalised edema & 12 & 37.50 & 20 & 62.50 & 32 \\
\hline
\end{tabular}

Table 3: Distribution of patients according to urine albumin.

\begin{tabular}{|c|c|c|c|c|c|c|c|c|c|}
\hline \multirow{2}{*}{$\begin{array}{l}\text { Urine } \\
\text { albumine }\end{array}$} & \multicolumn{9}{|c|}{ Clinical diagnosis } \\
\hline & NT & $\%$ & APE & $\%$ & SPE & $\%$ & Total & $\%$ & p value \\
\hline absent & 50 & 100.00 & 0 & 0.00 & 0 & 0.00 & 50 & 50.00 & \multirow{6}{*}{$<0.000$} \\
\hline $1+$ & 0 & 0.00 & 0 & 0.00 & 1 & 3.13 & 1 & 1.00 & \\
\hline $2+$ & 0 & 0.00 & 3 & 16.67 & 23 & 71.88 & 26 & 26.00 & \\
\hline $3+$ & 0 & 0.00 & 15 & 83.33 & 6 & 18.75 & 21 & 21.00 & \\
\hline trace & 0 & 0.00 & 0 & 0.00 & 2 & 6.25 & 2 & 2.00 & \\
\hline total & 50 & 100.00 & 18 & 100.00 & 32 & 100.00 & 100 & 100.00 & \\
\hline
\end{tabular}

In APE group, out of 18 patient's majority of about 51 $(83.3 \%)$ had $3+$ proteinuria. In SPE group out of 32 patients $23(71.9 \%)$ had $2+$ protienuria. None of the patients in Group NT had proteinuria. The result of chisquare test shows that there is high association between urine albumin and clinical diagnosis ( $p$ value $<0.000$ ) (Table 3). In normal group majority of about $24(48.00 \%)$ samples had bleeding time in the range 161-210, followed by $18(36.00 \%)$ samples had bleeding time in the range 110-160, In APE group the $50 \%$ patients had bleeding time in the range 161-210, followed by 4 $(22.22 \%)$ had in the range $110-160,3(16.67 \%)$ had above 260. In SPE group out of 32 patients $13(40.63 \%)$ patients had bleeding time in the range 161-210, followed by $9(28.13 \%)$ had bleeding time above 260, 7 (21.88\%) had in the range 110-160 (Table 4).

Table 4: Distribution of patients according to bleeding time.

\begin{tabular}{|c|c|c|c|c|c|c|c|c|}
\hline \multirow{2}{*}{ Bleeding time } & \multicolumn{8}{|c|}{ Clinical diagnosis } \\
\hline & NT & $\%$ & APE & $\%$ & SPE & $\%$ & Total & $\%$ \\
\hline $110-160$ & 18 & 36 & 4 & 22.22 & 7 & 21.88 & 29 & 29 \\
\hline $161-210$ & 24 & 48 & 9 & 50 & 13 & 40.63 & 46 & 46 \\
\hline $211-260$ & 5 & 10 & 2 & 11.11 & 3 & 9.38 & 10 & 10 \\
\hline Above 260 & 3 & 6 & 3 & 16.67 & 9 & 28.13 & 13 & 13 \\
\hline Total & 50 & 100 & 18 & 100 & 32 & 100 & 100 & 100 \\
\hline
\end{tabular}

In normal group $15(30.00 \%)$ patients had clotting time between 200-250 sec, 14 (28.00\%) had between 301-350 sec, $11(22.00 \%)$ had between 251-300 sec, $5(10.00 \%)$ had between $351-400 \mathrm{sec}, 3(6.00 \%)$ had between 551$600 \mathrm{sec}$ and only $1(2.00 \%)$ had $40-450 \mathrm{sec}$ and $451-500$ sec. In APE group 4 (22.22\%) patients had clotting time in the range $351-400 \mathrm{sec}$, followed by $3(16.67 \%)$ had between $251-300,2(11.11 \%)$ had between ranges 200 $250 \mathrm{sec}, 301-350 \mathrm{sec}, 451-500 \mathrm{sec}, 501-550 \mathrm{sec}$ and 551$600 \mathrm{sec}$ and only one patent had clotting time between 402-450 sec. In SPE group highest number i.e. 9
(28.13\%) patients had clotting time between 251-300 sec, followed by $7(21.88 \%)$ had between $351-400 \mathrm{sec}, 5$ $(15.63 \%)$ had between 501-550 sec, 4 (12.50\%), 3 $(9.38 \%)$ and $2(6.25 \%)$ patients had clotting time between the ranges 301-350 sec, 551-600 sec and 200-250 sec respectively and only one patient had clotting time between 401-450 sec and 451-500 sec each (Table 5). In Normal group, more than $75 \%$ patients had prothrombin time between $12-16 \mathrm{sec}, 8(16.00 \%)$ had between $16.1-20$ sec, $3(6.00 \%)$ patients had prothrombin time above 24 sec. In APE group, more than $50 \%$ patients had prothrombin time between $12-16 \mathrm{sec}, 3$ (16.67\%) had 
between 20.1-24 sec, 2 (11.11\%) had between 16.1-20 sec and only one patient had prothrombin time above 24 sec. In SPE group also more than $50 \%$ patients had prothrombin time between $12-16 \mathrm{sec}, 8(25.00 \%)$ patients had prothrombin time above 24 Sec, 5 (15.63\%) had between $16.1-20 \mathrm{sec}$ and only $2(6.25 \%)$ patients had prothrombin time between 20.1-24 sec (Table 6).

Table 5: Distribution of patients according to clotting time.

\begin{tabular}{|lllllllll|}
\hline Clotting time & Clinical diagnosis & APE & \% & SPE & \% & Total & \% \\
\hline $200-250$ & 15 & 30.00 & 2 & 11.11 & 2 & 6.25 & 19 & 19 \\
\hline $251-300$ & 11 & 22.00 & 3 & 16.67 & 9 & 28.13 & 23 & 23 \\
\hline $301-350$ & 14 & 28.00 & 2 & 11.11 & 4 & 12.5 & 20 & 20 \\
\hline $351-400$ & 5 & 10.00 & 4 & 22.22 & 7 & 21.88 & 16 & 16 \\
\hline $401-450$ & 1 & 2.00 & 1 & 5.56 & 1 & 3.13 & 3 & 3 \\
\hline $451-500$ & 1 & 2.00 & 2 & 11.11 & 1 & 3.13 & 4 & 4 \\
\hline $501-550$ & 0 & 0.00 & 2 & 11.11 & 5 & 15.63 & 7 & 7 \\
\hline $551-600$ & 3 & 6.00 & 2 & 11.11 & 3 & 9.38 & 8 & 8 \\
\hline Total & 50 & 100.00 & 18 & 100 & 32 & 100 & 100 & 100 \\
\hline
\end{tabular}

Table 6: Distribution of patients according to prothrombin time.

\begin{tabular}{|c|c|c|c|c|c|c|c|c|}
\hline \multirow{2}{*}{ Prothrombin time } & \multicolumn{8}{|c|}{ Clinical diagnosis } \\
\hline & NT & $\%$ & APE & $\%$ & SPE & $\%$ & Total & $\%$ \\
\hline $12-16$ & 39 & 78 & 12 & 66.67 & 17 & 53.13 & 68 & 68 \\
\hline $16.1-20$ & 8 & 16 & 2 & 11.11 & 5 & 15.63 & 15 & 15 \\
\hline $20.1-24$ & 0 & 0 & 3 & 16.67 & 2 & 6.25 & 5 & 5 \\
\hline Above 24 & 3 & 6 & 1 & 5.56 & 8 & 25 & 12 & 12 \\
\hline Total & 50 & 100 & 18 & 100 & 32 & 100 & 100 & 100 \\
\hline
\end{tabular}

In normal group $22(44.00 \%)$ patients had activated thromboplastin time between 26.1-30 sec, 13 (26.00\%) had between 31.-34 Sec, 12 (24.00\%) had between 22.26 sec and only three patients had $>34$ sec. In APE group 7 $(38.89 \%)$ patients had activated thromboplastin time between 22-26 sec, 6 (33.33\%) had between 26.1-30 sec,
$4(22.22 \%)$ had $>34$ sec and only one patient had between 30.1-34 sec. In SPE group highest number of patients had activated thromboplastin time between $22-26 \mathrm{sec}$, followed by $10(31.25 \%)$ had $>34 \mathrm{sec}, 9(28.13 \%)$ had between 26.1-30 sec and only three patients had between 30.1-34 sec (Table 7).

Table 7: Distribution of patients according to activated thromboplastin time.

\begin{tabular}{|c|c|c|c|c|c|c|c|c|}
\hline \multirow{2}{*}{$\begin{array}{l}\text { Activated thrombop- } \\
\text { lastin time }\end{array}$} & \multicolumn{8}{|c|}{ Clinical diagnosis } \\
\hline & NT & $\%$ & APE & $\%$ & SPE & $\%$ & Total & $\%$ \\
\hline $22-26$ & 12 & 24 & 7 & 38.89 & 10 & 31.25 & 29 & 29 \\
\hline $26.1-30$ & 22 & 44 & 6 & 33.33 & 9 & 28.13 & 37 & 37 \\
\hline $30.1-34$ & 13 & 26 & 1 & 5.56 & 3 & 9.38 & 17 & 17 \\
\hline Above 34 & 3 & 6 & 4 & 22.22 & 10 & 31.25 & 17 & 17 \\
\hline Total & 50 & 100 & 18 & 100 & 32 & 100 & 100 & 100 \\
\hline
\end{tabular}

In normal group lore than $50 \%$ patients had platelet count between 2.1-3 i.e. $26(52.00 \%)$, followed by 17 (34.00\%) had between $1.1-2,4(8.00 \%)$ had above 3 and again lowest patients had between 0-1. In APE group, out of 18 patients highest number of patients had platelet count between $2.1-3$ i.e. $8(44.44 \%)$, followed by $4(22.22 \%)$ had between $0-1,3(16.67 \%)$ had between $1.2-2$ and above 3. In SPE group also highest number of patients had platelet count between 2.1-3 i.e.12 (37.50\%) and lowest between $0-1$ i.e. $3(6.00 \%)$ (Table 8). 
Table 8: Distribution of patients according to platelet count.

\begin{tabular}{|lllllllll|}
\hline Platelet count & Clinical diagnosis & & & & & Total & \% \\
\hline $0-1$ & NT & \% & APE & \% & SPE & \% & Tot & 16 \\
\hline $1.1-2$ & 3 & 6.00 & 4 & 22.22 & 9 & 28.13 & 16 & 26 \\
\hline $2.1-3$ & 17 & 34.00 & 3 & 16.67 & 6 & 18.75 & 26 & 26 \\
\hline Above 3 & 26 & 52.00 & 8 & 44.44 & 12 & 37.5 & 46 & 46 \\
\hline Total & 4 & 8.00 & 3 & 16.67 & 5 & 15.63 & 12 & 12 \\
\hline
\end{tabular}

Table 9: Distribution of patients according to D-Dimer.

\begin{tabular}{|lllllllll|}
\hline D dimer & Clinical diagnosis & & & & & Total & \% \\
\hline $200-1200$ & NT & \% & APE & \% & SPE & \% & 26 & 26 \\
\hline $1201-2200$ & 22 & 44 & 2 & 11.11 & 2 & 6.25 & 26 \\
\hline $2201-3200$ & 22 & 44 & 1 & 5.56 & 4 & 12.5 & 27 & 27 \\
\hline $3201-4200$ & 2 & 4 & 3 & 16.67 & 9 & 28.13 & 14 & 14 \\
\hline Above 4200 & 0 & 0 & 8 & 44.44 & 4 & 12.5 & 12 & 12 \\
\hline Total & 4 & 8 & 4 & 22.22 & 13 & 40.63 & 21 & 21 \\
\hline & $\mathbf{5 0}$ & $\mathbf{1 0 0}$ & $\mathbf{1 8}$ & $\mathbf{1 0 0}$ & $\mathbf{3 2}$ & $\mathbf{1 0 0}$ & $\mathbf{1 0 0}$ & $\mathbf{1 0 0}$ \\
\hline
\end{tabular}

In group NT almost $88 \%$ patients had D-Dimer between 200-2200 and none of the patients had D-Dimer between $3201-4200$. In group APE $8(44.44 \%)$ patients had DDimer between 3201-4200, 4 (22.22\%) had above 4200 , 3 (16.67\%) had between 2201-3200, 2 (11.11\%) had between 200-1200 and only one patient had between 1201-2200. In SPE group 13 (40.63\%) patients had DDimer above 4200 , followed by $9(28.13 \%)$ had between 2201-3200, 4 (12.50\%) had between 1201-2200 and 3201-4200 and only two patients had between 200-1200 (Table 9).

\section{DISCUSSION}

Pre-eclampsia has remained a significant public health threat in both developed and developing countries contributing to maternal and perinatal morbidity and mortality globally. ${ }^{6}$ Women with mild pre-eclampsia generally have no symptoms. Women with severe preeclampsia may present with symptoms such as headache, upper abdominal pain, or visual disturbances and have raised blood pressure, ankle oedema and proteinuria. ${ }^{6}$

Almost one-third of the respondents had reported symptoms suggestive of pre-eclampsia i.e. $94.44 \%$ reported swelling of lower limb in APE group, followed by $77.78 \%$ of headache, $77.78 \%$ of generalized edema, $33.33 \%$ of vomiting, $22.22 \%$ of epigastirc pain and $11.11 \%$ visual disturbance in APE group. Similarly, $93.75 \%$ of swelling of lower limbs, $37.50 \%$ of generalized edema, $28.13 \%$ of headache, $9.28 \%$ of epigastric pain, $3.31 \%$ of vomiting, and $3.31 \%$ of visual disturbance in SPE group. Our findings were in agreement with other authors who have mentioned headache, blurring of vision, and right upper abdominal pain in severe cases of PIH, and William's Obstetrics and McKay. ${ }^{7}$

Proteinuria is the most important defining criterion in the diagnosis of pre-eclampsia. The acute onset of proteinuria in women with chronic hypertension is suggestive of superimposed pre-eclampsia. The findings of the present study revealed that $83.3 \%$ of APE group pregnant women had $3+$ proteinuria and $71.9 \%$ had $2+$ proteinuria. The $p$ value showed the highest significance between the urine albumin and clinical diagnosis. Howie et al (1971) found proteinuria of $0.19 \mathrm{gm} / \mathrm{dl}$ (Nil-0.35) in mild preeclampsia and $5.15 \mathrm{gm} / \mathrm{dl}(1.5-10)$ in severe preeclampsia. ${ }^{8}$ Lopez-Lleraet al (1976) found proteinuria of $4.15 \mathrm{gm} / \mathrm{L}$ in severe pre-eclampsia. Proteinuria in women in our study correlates well with other authors. ${ }^{9}$ Many authors found no correlation of bleeding time with severity of preeclampsia and found prolonged bleeding time only in cases with frank evidence of DIC. But the results of our study showed that even though the values lie in the within normal range, there is an increasing trend from NT to SPE group i.e. mean of 178.48 \pm 41.1 , $198.11 \pm 52.84$ and $209.31 \pm 65.34$ sec respectively. Which is similar to the observations in studies conducted by Dube et al (1975), Agrawal et al (1978), Antony et al Jambhulkar et al. ${ }^{10-12}$

Descriptive statistics of mean clotting time was $15.81 \pm 2.74,17.12 \pm 3.92$ and $18.19 \pm 4.96 \mathrm{sec}$ respectively for group NT, APE and SPE group. It was observed that there is very slight prolongation but not significant prolongation of clotting time. In our study clotting time was prolonged for 2 cases in APE and 3 cases in SPE. Many authors found no correlation between CT and severity of preeclampsia. Our findings of abnormal CT in 
SPE and APE were in agreement with other authors Dube et al, Agrawal et al, Antony et al, Jambhulkar et al. ${ }^{10-12}$

The prothrombin time in NT, APE and SPE was $28.97 \pm 4.44,30.51 \pm 7.98$ and $32.47 \pm 8.77$ sec respectively. The PT again was slightly prolonged as compared to healthy pregnant control but it was not significant. The PT was prolonged in some cases in which BT and CT were prolonged. Howie et al described PT of $13.6 \pm 1.6$, $13.2 \pm 1.3$ and $13.6 \pm 1.2 \mathrm{sec}$ in normal control, mild preeclampsia and severe preeclampsia respectively and found no significant variation. Agrawal et al, Kelton et al, Antony et al, Jambhulkar et al, Osmanagaoglu et al (2005) reported similar findings. K de Boer et al found prolonged PT in $7.4 \%$ of severe preeclampsia women, Leduc et al 16 reported 2\%, Metz et al reported $4 \%$ while Barron et al 17 reported $1.9 \%$ cases with prolonged PT. ${ }^{10-15}$ Our findings also correlate well with other authors. The activated partial thromboplastin time (a P.T.T.) with in NT, APE and SPE was 2.12 \pm 0.82 , $2.03 \pm 0.87$ and $2.08 \pm 1.05 \mathrm{sec}$ respectively and was not significantly prolonged when compared with healthy pregnant controls. Antony et al and Jambhulkar et al noted no significant difference of a P.T.T. The finding of a P.T.T in our study correlates well with other studies.

Various studies reported the functional abnormalities of platelets in the form of prolonged bleeding time in some women with pre-eclampsia. This platelet function abnormality along with decreased platelet count may be one of the end organ manifestations of pre-eclampsia and may consitiute an additional risk to patients with preeclampsia. Howieet al found platelet count in normal pregnant women as $215,000 /$ cumm and in mild preeclampsia as 168,000/cumm ( $\mathrm{p}<0.01)$ and 142,000/cumm $(\mathrm{p}<0.01)$ in severe preeclampsia, and explained the reduced platelet count due to consumption during intravascular coagulation. ${ }^{32}$ Bonnar et al showed platelet count of $203 \pm 60 \times 103 /$ cumm in control group and $140 \pm 39$ x 103/cumm, a highly significant thrombocytopenia $(\mathrm{P}<0.01)$ in severe preeclampsia. Giles et al found platelet count in control- 286 $\pm 68.7 \mathrm{x}$ $103 /$ cumm, mild preeclampsia $220 \pm 62$ x 103/cumm $(\mathrm{p}<0.05)$ and $155 \pm 69 \times 103 /$ cumm $(\mathrm{p}<0.01)$ in severe preeclampsia. $^{18,19}$

Pritchard et al noted no significant change in platelet count in mild preeclampsia but significantly decreased count in eclampsia when compared with normal pregnant control. ${ }^{20}$ Kulkarni et al found increase in severity in thrombocytopenia with increasing severity of preeclampsia. Kelton et al described 34\% thrombocytopenia in pre-eclampsia, Trofatter et al found significant thrombocytopenia $(\mathrm{P}<0.05)$ in $17.9 \%$ in severe preeclampsia. Dekker et al found $7 \%$ thrombocytopenia in mild preeclampsia and $50 \%$ in severe preeclampsia and $20 \%$ in all cases of eclampsia. ${ }^{21,22}$ Leduc et al described $20 \%$ thrombocytopenia in severe preeclampsia. Metz et al reported $4 \%$ and $7 \%$ thrombocytopenia is mild and severe preeclampsia. Antony et al noted normal platelet count in mild preeclampsia when compared with control group. Joshi et al reported reduction in platelet count of severe eclampsia $(\mathrm{p}=0.001)$ and mild $(\mathrm{p}=0.044)$ when compared to control group. J. Prakash found thrombocytopenia in $16.66 \%$ of his pre-eclamptic patients and marked reduction in $11.11 \%$ ( 8 patients) especially in cases of HELLP syndrome (5 patients) and eclampsia (3 patients). Our findings were in agreement with other authors who have mentioned above because the finding showed even though the values lies within normal range, but there is an increasing trend from group NT to APE i.e. mean $309.6 \pm 88.9, \quad 369.6 \pm 111.6, \quad 378.6 \pm 115.59 \times \quad 103 /$ cumm respectively and analysis of variance showed that there is significant difference between mean platelet count of the groups NT, SPE and APE. ${ }^{23}$

Pre-eclampsia is characterized by the deposition of fibrin in the walls of small blood vessels. D-dimer is used as a marker for degradation of fibrin in vivo. So, D-dimer has emerged as a useful indicator in the diagnosis of thrombotic conditions because its plasma concentration has a high predictive value for the assessment of severity of DIC.

In the current study, D-dimer levels of pre-eclamptic women as compared to normal controls were significantly high which correlates with the study conducted by $\mathrm{Z}$ Tacoosianet al. The results of the present study revealed that high values i.e. 3201 to 4200 and above 4300 are seen in patients with hemoglobin range of $7-9 \mathrm{~g} / \mathrm{dL}$. Similar results were also reported by KucukgozGulec U et al where D-Dimer levels were significantly higher in study group than the control group and it was also significantly higher in the patients with severe pre-eclampsia than mild pre-eclampsia. ${ }^{24,25}$ Also, Trofatter et al noted greater percentage of thrombocytopenia in $\mathrm{D}$ dimer positive patients, than in Ddimer negative patients.

Patients those who had higher the D-Dimer value, their systolic blood pressure were also high and similarly their diastolic blood pressure was also high and vice versa. Study conducted by Rehman et al showed that the mean systolic and diastolic blood pressures in patients with plasma D-dimer $>0.5 \mu \mathrm{g} / \mathrm{ml}$ were considerably higher than those who had plasma D-dimer $\leq 0.5 \mu \mathrm{g} / \mathrm{ml}$ ( $\mathrm{p}<0.001$ ), and the study also showed that majority $(81.8 \%)$ of preeclamptic women with plasma D-dimer $>0.5 \mu \mathrm{g} / \mathrm{ml}$ had systolic blood pressure $\geq 160 \mathrm{~mm} \mathrm{Hg}$ compared to $46.4 \%$ of those who had plasma D-dimer $\leq 0.5 \mu \mathrm{g} / \mathrm{ml}(\mathrm{p}=0.010)$. Our finding also strongly supports the reported data. ${ }^{26}$

The results of cross tabulation revealed that out of 17 patients who had DIC showed the D-Dimer value of above 4200 which is highly significant. similar results were seen in various studies conducted by Bonnar $\mathrm{J}$ et al, Carr JM, McKinney M, McDonagh J, Similarly the cross tabulation of D-Dimer and follow up showed that 3 out of 21 patients who died had the Di-Dimer value of above 4200. ${ }^{18,27}$ 


\section{CONCLUSION}

This study suggests that, pregnant women at risk of preeclampsia should be identified early and high-quality antenatal care should be provided in order to minimize the complications of pre-eclampsia both for the mother and the fetus. This study shows that even with the normal routine coagulation parameters, D dimer was significantly elevated in both subclinical and clinical DIC. So, D dimer is a specific tool in early diagnosis and deciding appropriate management of complications of $\mathrm{PIH}$, and also, recommends the health authorities to strengthen the maternal health programs focusing on the prevention and control of the risk factors during the pre pregnancy period.

Funding: No funding sources

Conflict of interest: None declared

Ethical approval: The study was approved by the Institutional Ethics Committee

\section{REFERENCES}

1. Stirling Y, Woolf L, North WR, Seghatchian MJ, Meade TW. Haemostasis in normal pregnancy, Thromb Haemost. 1984;52:176-82.

2. Ludwig H. Hemorrhagic disorders in pregnancy. Ther Umsch. 1999;56:608-15.

3. Bremme KA. Haemostatic changes in pregnancy. Bests Pract Res Clin Haematol. 2003;16(2):153-8.

4. Gary Cunningham F, Kenneth J. Leveno, Steven L. Bloom, John C. Hauth, Dwight J. Rouse, Catherine Y. Spong. Williams obstetrics- 23rd Edition. New York, NY: McGraw-Hill; 2010:706-56.

5. Srivastava M, Bali S, Pandey J, Nayar V, Talib VH. Pregnancy Induced Hypertension and Antithrombin-III. Indian J Pathol Microbiol. 1995;38(3):257-60.

6. Duley L. Maternal mortality associated with hypertensive disordersof pregnancy in Africa, Asia, Latin America and the Caribbean. Br J ObstetGynaecol. 1992;99:547-53.

7. McKay DG. Hematology evidence of disseminatedintravascular coagulation in eclampsia. Obs and GynSurvey. 1972;27(6):399-417.

8. Howie PW, Prentice CRM, McNicol GP. Coagulation, fibrinolysis and platelet function in preeclampsia, essential hypertension and placental insufficiency. BJOG: An International Journal of Obstetrics and Gynaecology. 1971;78(11):992-1003.

9. Lopez - Llera M, Espinosa ML, Lion MD, Linares GR. Abnormal coagulation and fibrinolysis in eclampsia. Am J Obs Gyn. 1976;124(7):681-87.

10. Agrawal S, Buradkar A. Coagulation studies in toxaemias of pregnancy. $\mathrm{J}$ Obstet Gynecol India. 1978;992-96.

11. Antony $\mathrm{T}$, Suresh $\mathrm{H}$, Kadam S, Shashikala P, Chandrasekhar HR. Coagulation profile in pregnancy induced hypertension (PIH). Ind. J. Hemat. Blood Transf. 1998;16(1):7-11.
12. Jambhulkar S, Shrikhande A, Shrivastava R, Deshmukh K. Coagulation profile in pregnancy induced Ind. J. Hemat. Blood Transf. 2001;19(1):35.

13. Kelton JG, Hunter DJS, Neame PB. A platelet functiondefect in preeclampsia. Obs Gyn. 1985;65(1):107-09.

14. Osmanağaoğlu MA, Topçuoğlu K, Ozeren M, Bozkaya H. Coagulation inhibitors in preeclamptic pregnantwomen. Arch Gynecol Obstet. 2005;271(3):227-30.

15. Boer KD, Buller HR, Ten Cate JW, Treffers PE. Coagulation studies in the syndrome of haemolysis, elevated liver enzymes and low platelets. Bri $\mathbf{J}$ of Obsand Gyn. 1991;98:42-7.

16. Leduc L, Wheeler JM, Kirshon B, Mitchell P, CottonDB. Coagulation profile in severe pre-eclampsia. Obs Gyn. 1992;79(1):14-8.

17. Barron WM, Heckerling P, Hibbard JU, Fisher S. Reducing unnecessary coagulation testing in hypertensive disorders of pregnancy. Obs Gyn. 1999;94:364-70.

18. Bonnar J, McNicol GP, Douglas AS. Coagulation andfibrinolytic systems in preeclampsia and eclampsia. Brit Med Jour. 1971;2:12-6.

19. Giles C, Inglis TCM. Thrombocytopenia and macrothrombocytosis in gestational hypertension. Bri J of Obs and Gyn. 1981;88:1115-19.

20. Pritchard JA, Cunningham FG, Mason A. Coagulation changes in pre-eclampsia: Their frequency and pathogenesis. Am J of Gyn Obs. 1976;124(8):855-59.

21. Trofatter KF, Howell ML, Greenberg CS, Hage ML. Screening of the D-Dimer in screening for coagulation abnormalities in pre-eclampsia. Obs Gyn. 1989;73(3):435-39.

22. Dekker GA, Sibai BM. Early detection of preeclampsia. Am J Obs Gyn. 1991;165(1):160-75.

23. Joshi. Platelet estimation: Its prognostic value in pregnancy induced hypertension. Indian $\mathrm{J}$ Physiol Pharmacol. 2004;51(2):160-64.

24. Tacoosian Z, Javadi HE, Farzam S, Javadi A. Evaluation of correlation between pre-eclampsia with D-Dimer. The Journal of Qazvin University of Medical Sciences. 2007;11(1):62-6.

25. KucukgozGulec U, TuncayOzgunen F, BarisGuzel A, Buyukkurt S, Seydaoglu G, FerhatUrunsak I, et al. An analysis of C-reactive protein, procalcitonin, and Ddimer in pre-eclamptic patients. Am J Reprod Immunol. 2012;68(4):331-7.

26. Rahman R, Begum K, Khondker L, Majumder NI, Nahar K, Sultana R, Siddika A. Role of D-dimer in determining coagulability status in pre-eclamptic and normotensive pregnant women. Mymensingh Med J. 2015; 24(1):115-20.

27. Carr JM, McKinney M, McDonagh J. Diagnosis of disseminated intravascular coagulation. Role of Ddimer Am J Clin Pathol. 1989;91(3):280-7.

Cite this article as: Upadhyaya R, Sannaboraiah A, Donimath KV. The comparative study of fibrin degradation products in normal pregnancy and pregnancy induced hypertension. Int J Reprod Contracept Obstet Gynecol 2017;6:1258-64. 